\title{
Total protein, albumin and low-molecular-weight protein excretion in HIV-positive patients
}

Lucy J Campbell ${ }^{1}$, Tracy Dew², Rashim Salota², Emily Cheserem³, Lisa Hamzah ${ }^{1,3}$, Fowzia Ibrahim¹,

Pantelis A Sarafidis ${ }^{1}$, Caje F Moniz ${ }^{2}$, Bruce M Hendry ${ }^{1}$, Mary Poulton ${ }^{3}$, Roy A Sherwood ${ }^{2}$ and Frank A Post ${ }^{1,3^{*}}$

\begin{abstract}
Background: Chronic kidney disease is common in HIV positive patients and renal tubular dysfunction has been reported in those receiving combination antiretroviral therapy (CART). Tenofovir (TFV) in particular has been linked to severe renal tubular disease as well as proximal tubular dysfunction. Markedly elevated urinary concentrations of retinal-binding protein (RBP) have been reported in patients with severe renal tubular disease, and low-molecular-weight proteins (LMWP) such as RBP may be useful in clinical practice to assess renal tubular function in patients receiving TFV. We analysed 3 LMWP as well as protein and albumin in the urine of a sample of HIV positive patients.
\end{abstract}

Methods: In a cross-sectional fashion, total protein, albumin, RBP, cystatin C, and neutrophil gelatinase-associated lipocalin (NGAL) were quantified in random urine samples of $317 \mathrm{HIV}$ positive outpatients and expressed as the ratio-to-creatinine (RBPCR, CCR and NGALCR). Exposure to CART was categorised as none, CART without TFV, and cART containing TFV and a non-nucleoside reverse-transcriptase-inhibitor (TFV/NNRTI) or TFV and a protease-inhibitor (TFV/PI).

Results: Proteinuria was present in $10.4 \%$ and microalbuminuria in $16.7 \%$ of patients. Albumin accounted for approximately $10 \%$ of total urinary protein. RBPCR was within the reference range in $95 \%$ of patients while NGALCR was elevated in $67 \%$ of patients. No overall differences in urine protein, albumin, and LMWP levels were observed among patients stratified by CART exposure, although a greater proportion of patients exposed to TFV/PI had RBPCR $>38.8 \mu \mathrm{g} / \mathrm{mmol}(343 \mu \mathrm{g} / \mathrm{g})(\mathrm{p}=0.003)$. In multivariate analyses, black ethnicity $(\mathrm{OR} 0.43,95 \% \mathrm{Cl} 0.24$, $0.77)$ and $\mathrm{eGFR}<75 \mathrm{~mL} / \mathrm{min} / 1.73 \mathrm{~m}^{2}$ (OR $\left.3.54,95 \% \mathrm{Cl} 1.61,7.80\right)$ were independently associated with upper quartile (UQ) RBPCR. RBPCR correlated well to CCR $\left(r^{2}=0.71\right)$, but not to NGALCR, PCR or ACR.

Conclusions: In HIV positive patients, proteinuria was predominantly of tubular origin and microalbuminuria was common. RBPCR in patients without overt renal tubular disease was generally within the reference range, including those receiving TFV. RBP therefore appears a promising biomarker for monitoring renal tubular function in patients receiving TFV and for distinguishing patients with normal tubular function or mild tubular dysfunction from those with severe renal tubular disease or Fanconi syndrome.

Keywords: Proteinuria, Albuminuria, Retinol-binding protein, RBP, Cystatin C, Neutrophil gelatinase-associated lipocalin, NGAL, Tenofovir, HIV

\footnotetext{
* Correspondence: frank.post@kcl.ac.uk

${ }^{1}$ Academic Department of Renal Sciences, King's College London, London, United Kingdom

${ }^{3}$ Sexual Health, King's College Hospital, London, United Kingdom

Full list of author information is available at the end of the article
} 


\section{Background}

Chronic kidney disease (CKD) is present in approximately $15 \%$ of HIV positive patients [1]. Uncontrolled HIV replication has been associated with the development of HIV-associated nephropathy (HIVAN) [2-4], CKD progression and loss of kidney function $[3,5,6]$, while the use of combination antiretroviral therapy (cART) may improve renal function [7-9], reduce the incidence of acute renal failure [10], and delay progression to end-stage kidney disease $[3,11,12]$. However, specific antiretrovirals including tenofovir (TFV), indinavir and atazanavir have been associated with the development or progression of CKD [13-15], and current guidelines recommend screening for CKD at baseline in all HIV infected patients, and regularly thereafter for all or those at increased risk of CKD using estimated glomerular filtration rate (eGFR) and urinalysis [16-18].

Renal tubular disease and Fanconi syndrome have emerged as clinically significant complications of cART, and are most commonly observed with TFV [19]. The majority of reported cases of Fanconi syndrome have arisen in patients aged $>40$ years who received TFV together with didanosine or ritonavir-boosted protease inhibitors (TFV/PI) [20-23]. Milder forms of tubular dysfunction (defined by variable criteria) have been reported in 12-81 \% of HIV positive patients on cART [24-27]. In these studies, tubular dysfunction was associated with older age [24,26-28], lower weight or BMI [26,27], diabetes mellitus [29], use of TFV [24,26,29-31] or TFV/PI [26], and with genetic polymorphisms in subjects exposed to TFV $[28,32]$.

In patients with tubular dysfunction or Fanconi syndrome, an impaired ability of the proximal renal tubule to reabsorb phosphate, glucose, urate, amino acids and low molecular weight proteins (LMWP) from the glomerular ultrafiltrate results in increased urinary loss of these molecules. Retinol-binding protein (RBP) and cystatin $\mathrm{C}$ are examples of LMWP that are found in increased amounts in urine from patients with Fanconi syndrome [21,33]. It has been proposed that these biomarkers may be useful in the diagnosis of Fanconi syndrome and to monitor and detect tubular dysfunction in patients receiving TFV [34]. Neutrophil gelatinaseassociated lipocalin (NGAL) is another LMWP, which is highly induced during inflammation and found to be a sensitive, early marker of acute kidney injury [35]. However, concentrations of these LMWP in urine of HIV positive patients and their associations with demographic and clinical parameters have not been well defined.

The objective of the present study was to examine the concentrations of different LMWP (RBP, cystatin C and NGAL) in relation to total protein and albumin excretion in urine of HIV positive patients, and to investigate possible factors associated with the highest quartile of urinary concentrations of these LMWP, with particular emphasis on the type of cART used.

\section{Methods}

\section{Study population}

We conducted a cross sectional study of consecutive HIV positive outpatients who attended King's College Hospital, London, UK between 8/2006 and 8/2007. Patients were included if they agreed to participate in the study irrespective of the presence of kidney disease or risk factors for kidney disease. The study was approved by the local NHS research ethics committee (LREC) and all subjects provided informed consent.

For each subject, demographic, clinical and laboratory data were obtained from the clinic database and electronic hospital records. In addition, a detailed medical history was obtained, and height, weight, and waist circumference were measured. Three clinic blood pressure (BP) measurements were recorded of which the average of the second and third reading was used for the analysis. Blood samples were taken for routine biochemistry including renal, liver, bone, and lipid profiles, full blood count, CD4 T cell count and HIV RNA level. In addition, spot urine samples were obtained for measurement of creatinine, protein and albumin; an aliquot of urine was stored at $-70^{\circ} \mathrm{C}$ for measurement of RBP, cystatin C and NGAL.

\section{Definitions}

A diagnosis of hypertension was based on levels of systolic BP $\geq 140$ or diastolic BP $\geq 90 \mathrm{mmHg}$ or current treatment of hypertension with antihypertensive drugs [36]. Diabetes was defined by a prior diagnosis by a health care professional, use of anti-hyperglycaemic medication, or the need to follow a diabetic diet. eGFR was calculated with the 4-variable Modification of Diet in Renal Disease (MDRD) equation, incorporating age, gender and ethnicity [17]. Proteinuria was defined as urine protein-to-creatinine ratio (PCR) $>20 \mathrm{mg} / \mathrm{mmol}$ (approximately $>200 \mathrm{mg} / \mathrm{g}$ ), macroalbuminuria as albuminto-creatinine ratio (ACR) $>30 \mathrm{mg} / \mathrm{mmol}$ (approximately $>300 \mathrm{mg} / \mathrm{g}$ ), and microalbuminuria as ACR $3-30 \mathrm{mg} /$ mmol (approximately 30-300 mg/g), respectively. Exposure to cART was categorised as none, cART not containing TFV, cART containing TFV and a non-nucleoside reverse transcriptase inhibitor but no PI (TFV/NNRTI), or cART containing TFV/PI.

\section{Analytical methods}

Urine albumin was measured using a polyethylene enhanced immunoturbidimetric assay, urine protein using the pyrogallol red method and creatinine with the kinetic Jaffe method on the ADVIA 2400 analyser (Siemens Healthcare Diagnostics Ltd, Camberley, UK). 
Retinol-binding protein was measured by enzyme-linked immunosorbent assay (ELISA; Immundiagnostik, Bensheim, Germany; reference range 0.01-0.54 mg/L), cystatin $\mathrm{C}$ by latex-enhanced immunoturbidimetric assay (Siemens Healthcare Diagnostics Ltd, Camberley, UK; no reference range supplied), and NGAL by ELISA (BioPorto Diagnostics, Gentofte, Denmark, reference range 0.7-9.8 $\mu \mathrm{g} / \mathrm{L}$ ), all with intra- and inter-assay variability of $<5 \%$ and $<10 \%$ respectively. For reasons of comparison, the urinary concentration of all LMWP was expressed relative to the urinary creatinine concentration (in $\mathrm{mmol} / \mathrm{L}$ or $\mathrm{g} / \mathrm{L}$ ) as $\mathrm{RBP} /$ creatinine ratio (RBPCR), cystatin $\mathrm{C} /$ creatinine ratio (CCR), and NGAL/creatinine ratio (NGALCR).

\section{Statistical analysis}

Statistical analyses were performed using STATA version 11 (StataCorp, College Station, TX, USA). Categorical variables are presented as absolute frequencies and the relevant percentages. Depending on the distribution, continuous variables are presented as means \pm standard deviation (mean $\pm \mathrm{SD}$ ) or as medians with inter-quartile ranges. In view of their skewed distribution, PCR, ACR and LMWP measurements were also compared following $\log$ transformation. Clinical and laboratory parameters were described, and compared for patients stratified by cART regimen using chi-squared or Fisher's exact test (categorical variables), Analysis of Variance or Kruskal-Wallis test (continuous variables). Correlations between the different LMWP and PCR were assessed using Pearson's correlation coefficient, following log transformation of RBPCR and PCR, and square root transformation of CCR and NGALCR, in view of their skewed distribution.

The assays to quantify LMWP in urine are poorly standardised and the reference ranges for persons without kidney disease have not been widely validated. Hence, factors associated with the upper quartile (UQ) of RBPCR, CCR and NGALCR measurements were examined in logistic regression analyses. Variables were tested for interaction and included in the multivariate models if $\mathrm{p}$ was $<0.05$ in univariate analysis.

\section{Results}

A total of 317 patients were studied. Demographic and clinical characteristics of the study cohort are depicted in Table 1 . The mean age was 41 years, $70 \%$ of patients were men, $60 \%$ of black ethnicity, and HIV infection was acquired through sex between men and IV drug use in $40 \%$ and $2 \%$ respectively. The median nadir and current CD4 count of the patients were 171 and 389 cells $/ \mathrm{mm}^{3}$ respectively, $82 \%$ were taking cART at the time of sampling, and $65 \%$ had plasma HIV RNA levels $<50$ copies/ $\mathrm{mL}$. The median eGFR was $89 \mathrm{~mL} / \mathrm{min} / 1.73 \mathrm{~m}^{2}$; of note, only $4 \%$ and $2 \%$ of patients respectively had eGFR $<60$ and $<50 \mathrm{~mL} / \mathrm{min} / 1.73 \mathrm{~m}^{2}$. Hypertension and diabetes mellitus was present in $15 \%$ and $4 \%$ of patients respectively, and $5 \%$ and $6 \%$ were co-infected with hepatitis B or C (Table 1).

As shown in Table 1, there were no significant differences between the groups of patients in terms of age, gender and ethnicity, with the exception of fewer men who received cART without tenofovir. Progressive increases from naive patients to patients receiving TFV/ PI were noted in time since HIV diagnosis and time since starting cART. Patients receiving CART had lower nadir CD4 cell counts and more often experienced an AIDS-defining illness.

Proteinuria, macroalbuminuria and microalbuminuria were present in $10.4 \%, 0.6 \%$ and $16.7 \%$ of patients respectively. There were no significant differences in the levels of urine protein and albumin excretion between the groups studied, although a trend towards lower values among patients not receiving cART was observed (Table 2). In patients with proteinuria, the median ratio of ACR/PCR was $9.9(6.3,27.0)$ percent, suggesting that albumin was a relatively small fraction of total urinary protein. Of the LMWP, good correlation between RBPCR and CCR was observed $\left(r^{2}=0.71\right.$ [95\% CI 0.64 , 0.77]) (Figure 1A). By contrast, NGALCR correlated poorly with $\operatorname{RBPCR}\left(\mathrm{r}^{2}=0.12[0.008,0.22]\right)$ (Figure 1B) or CCR $\left(\mathrm{r}^{2}=0.03[-0.09,0.16]\right)$, and all LMWP correlated poorly with either PCR or ACR $\left(r^{2}<0.4\right)$ (Figure 1C-D).

We observed no significant differences in LMWP excretion between the groups compared. However, RBPCR values $>38.8 \mu \mathrm{g} / \mathrm{mmol}(>343.5 \mu \mathrm{g} / \mathrm{g})$, a threshold previously associated with clinically significant renal tubular disease [21], was present in 5-8\% of patients not receiving TFV/PI compared to $20 \%$ of those receiving TFV/PI $(\mathrm{p}=0.003)$, as shown in Figure 2. When applying the RBP and NGAL reference ranges provided by the manufacturers to our patients (using the median weight of $74.2 \mathrm{~kg}$ and assuming urine output of $0.5 \mathrm{~mL} / \mathrm{kg} / \mathrm{hr}$ ), 17 (5.4\%, including 4 patients exposed to TFV/NNRTI and 3 to TFV/PI) and 212 (66.9\%) of our patients had RBPCR and NGALCR measurements above the upper limit $(>48.1 \mu \mathrm{g} / \mathrm{mmol}[>425.8 \mu \mathrm{g} / \mathrm{g}]$ and $>873 \mathrm{ng} / \mathrm{mmol}$ $[>7724 \mathrm{ng} / \mathrm{g}]$, respectively).

In univariate analysis, older age, eGFR $<90 \mathrm{~mL} / \mathrm{min} /$ $1.73 \mathrm{~m}^{2}$, longer time since HIV diagnosis, and treatment with TFV/PI signified a higher odds ratio of UQ RBPCR, whereas black ethnicity was associated with reduced odds of UQ RBPCR (Table 3). After adjustment, ethnicity and eGFR $<75 \mathrm{~mL} / \mathrm{min} / 1.73 \mathrm{~m}^{2}$ were independently associated with UQ RBPCR, while a trend towards higher risk with TFV/PI was observed $(\mathrm{p}=0.10)$. Longer duration of TFV exposure was not associated with 
Table 1 Demographic and clinical characteristics of the total study population and the four study groups

\begin{tabular}{|c|c|c|c|c|c|c|c|c|c|}
\hline & & All patients & No cART & cART/no TFV & CART/TFV & p-value & TFV/NNRTI & TFV/PI & p-value \\
\hline Number of patients & $\mathrm{N}(\%$ of total) & $317(100)$ & $57(18)$ & $143(45)$ & $117(37)$ & & $72(23)$ & $45(14)$ & \\
\hline Age (years) & Mean (SD) (range) & 41.0 (8.9) $(24.4,64.3)$ & $38.0(8.5)(21.2,60.2)$ & 40.9 (8.9) $(25.8,63.3)$ & $42.3(8.8)(25.7,70.1)$ & 0.83 & $42.3(9.3)(21.7,65.8)$ & $42.6(7.3)(27.5,63.3)$ & 0.30 \\
\hline Male gender & $N(\%)$ & $222(70)$ & $43(75)$ & $89(62)$ & $90(77)$ & 0.02 & $54(75)$ & $36(80)$ & 0.53 \\
\hline Black Ethnicity & $N(\%)$ & $189(60)$ & $31(54)$ & $95(66)$ & $63(54)$ & 0.08 & $35(49)$ & $28(62)$ & 0.15 \\
\hline Time since HIV diagnosis (years) & Median (IQR) & $4.9(2.1,8.7)$ & $2.0(0.5,4.2)$ & $5.1(2.2,8.2)$ & $5.8(3.1,4.7)$ & 0.0001 & $5.1(2.5,8.2)$ & $7.8(4.1,11.4)$ & 0.003 \\
\hline Time since start CART (years) & Median (IQR) & $4.6(2.6,7.6)$ & $3.2(2.6,5.9)$ & $4.3(2.6,6.8)$ & $4.8(2.6,8.1)$ & 0.51 & $4.5(2.5,7.3)$ & $6.0(3.1,9.2)$ & 0.009 \\
\hline AIDS (CDC status C) & $(\mathrm{N}, \%)$ & $77(17)$ & $1(2)$ & $27(19)$ & $33(28)$ & $<0.0001$ & $17(24)$ & $16(35)$ & 0.16 \\
\hline Nadir CD4 count (cells/mm³) & Median (IQR) & $171(71,262)$ & $290(230,416)$ & $161(69,250)$ & $146(64,210)$ & 0.0001 & $158(82,224)$ & $94(25,222)$ & 0.07 \\
\hline Current CD4 count (cells/mm³) & Median (IQR) & $389(270,532)$ & $437(329,560)$ & $363(269,534)$ & $385(259,517)$ & 0.13 & $385(245,512)$ & $376(249,566)$ & 0.62 \\
\hline Current HIV RNA ( $\log 10)$ & Mean (SD) & $2.4(1.3)$ & $3.9(1.1)$ & $2.2(1.1)$ & $2.0(1.0)$ & 0.0001 & $2.1(1.1)$ & $2.1(1.0)$ & 0.04 \\
\hline HIV RNA $<50 \mathrm{c} / \mathrm{mL}$ & $N(\%)$ & $204(65)$ & $4(9)$ & $110(77)$ & $90(77)$ & $<0.0001$ & $60(83)$ & $30(67)$ & $<0.0001$ \\
\hline Hepatitis B surface Ag (positive) & $N(\%)$ & $15(5)$ & $3(5)$ & $4(3)$ & $8(7)$ & 0.31 & $4(6)$ & $4(9)$ & 0.49 \\
\hline Hepatitis C Antibody (positive) & $N(\%)$ & $20(6)$ & $3(5)$ & $3(2)$ & $14(12)$ & 0.005 & $10(14)$ & $4(9)$ & 0.42 \\
\hline eGFR (mL/min/1.73 m2) & Median (IQR) & $89(78,99)$ & $91(81,99)$ & $89(80,100)$ & $85(77,97)$ & 0.08 & $86(76,97)$ & $82(76,96)$ & 0.84 \\
\hline Diabetes & $N(\%)$ & $11(4)$ & $0(0)$ & $7(6)$ & $4(4)$ & 0.27 & $2(3)$ & $2(5)$ & 0.62 \\
\hline Hypertension & $N(\%)$ & $39(15)$ & $5(12)$ & $20(16)$ & $14(13)$ & 0.75 & $11(17)$ & $3(8)$ & 0.16 \\
\hline Weight (Kg) & Median (IQR) & $74.2(66.0,82.0)$ & $76.0(68.9,85.0)$ & $74.3(65.6,82.0)$ & $73.5(66.0,82.9)$ & 0.39 & $73.6(66.4,81.0)$ & $71.1(65.6,84.9)$ & 0.73 \\
\hline BMI & Median (IQR) & $24.6(22.9,28.1)$ & $25.6(22.5,31.4)$ & $25.5(22.4,29.6)$ & $23.9(21.9,27.1)$ & 0.06 & $24.1(22.1,26.8)$ & $23.5(21.4,27.7)$ & 0.73 \\
\hline
\end{tabular}

$\mathrm{P}$ value for comparison between study groups (significance relates to the group in bold).
CART = combination antiretroviral therapy; TFV = tenofovir; NNRTI = non-nucleoside reverse transcriptase inhibitor; $\mathrm{PI}=$ protease inhibitor; eGFR=estimated glomerular filtration rate; BMI = body mass index 
Table 2 Levels of total protein, albumin, low-molecular weight proteins in total and in the four study groups

\begin{tabular}{|c|c|c|c|c|c|c|c|c|c|}
\hline & & All patients & No cART & cART/no TFV & CART/TFV & $\mathrm{p}$-value & TFV/NNRTI & TFV/PI & $p$-value \\
\hline PCR (mg/g) & Median (IQR) & $82.8(56.2,134.6)$ & $73.4(52.5,111.8)$ & $84.7(58.8,134.2)$ & $82.7(56.2,141.9)$ & 0.33 & $82.9(60.9,141.3)$ & $82.6(50.2,158.0)$ & 0.88 \\
\hline $\log$ PCR (mg/g) & Mean (SD) & $4.53(0.85)$ & $4.37(0.66)$ & $4.58(0.93)$ & $4.52(0.82)$ & $>0.05$ & $4.53(0.82)$ & $4.50(0.83)$ & 0.82 \\
\hline ACR $(\mathrm{mg} / \mathrm{g})$ & Median (IQR) & $10.3(5.4,22.2)$ & $6.8(4.9,15.0)$ & $11.5(5.8,28.9)$ & $10.0(5.7,20.1)$ & 0.10 & 10.5 (5.7 18.8) & $9.6(5.5,24.9)$ & 0.26 \\
\hline Log ACR (mg/g) & Mean (SD) & $2.46(1.16)$ & $2.19(1.07)$ & $2.59(1.26)$ & $4.52(0.82)$ & $>0.05$ & $2.36(1.08)$ & $2.48(1.01)$ & 0.24 \\
\hline RBPCR $(\mu \mathrm{g} / \mathrm{g})$ & Median (IQR) & $66.4(25.5,150.4)$ & $61.4(15.1,124.6)$ & $60.4(24.5,130.4)$ & $75.5(28.2,169)$ & 0.24 & $75.23(27.2,138.7)$ & $75.5(30.6,241.3)$ & 0.27 \\
\hline $\log \operatorname{RBPCR}(\mu \mathrm{g} / \mathrm{g})$ & Mean (SD) & $3.92(1.75)$ & $3.64(1.94)$ & $3.86(1.69)$ & $4.13(1.71)$ & $>0.05$ & $4.02(1.66)$ & $4.32(1.78)$ & 0.58 \\
\hline NGALCR (ng/g) & Median (IQR) & $17993(6998,44823)$ & $19658(7919,44728)$ & $20049(7172,45319)$ & $14412(6011,43756)$ & 0.56 & $12770(5491,47963)$ & $17993(6998,42732)$ & 0.44 \\
\hline Log NGALCR (ng/g) & Mean (SD) & $9.52(1.99)$ & $9.39(2.36)$ & $9.67(1.82)$ & $9.40(1.99)$ & $>0.05$ & $9.40(1.90)$ & $9.40(2.17)$ & 0.99 \\
\hline CCR $(\mu \mathrm{g} / \mathrm{g})$ & Median (IQR) & $2.44(0.75,5.39)$ & $2.70(0.79,5.23)$ & $2.82(1.01,5.51)$ & $1.92(0.56,5.10)$ & 0.13 & $1.92(0.46,5.02)$ & $2.04(0.70,5.46)$ & 0.44 \\
\hline $\log C C R(\mu \mathrm{g} / \mathrm{g})$ & Mean (SD) & $0.80(1.71)$ & $0.64(1.47)$ & $1.12(1.82)$ & $0.50(1.65)$ & 0.02 & $0.35(1.66)$ & $0.76(1.63)$ & 0.29 \\
\hline
\end{tabular}

$\mathrm{p}$ value for comparison between study groups.

$\mathrm{PCR}=$ protein-creatinine ratio (urine); $\mathrm{ACR}=$ albumin-creatinine ratio (urine); $\mathrm{RBPCR}=$ retinol-binding protein-creatinine ratio (urine); $N G A L C R=$ neutrophil gelatinase-associated lipocalin-creatinine ratio (urine); $\mathrm{CCR}=$ cystatin C-creatinine ratio (urine). 


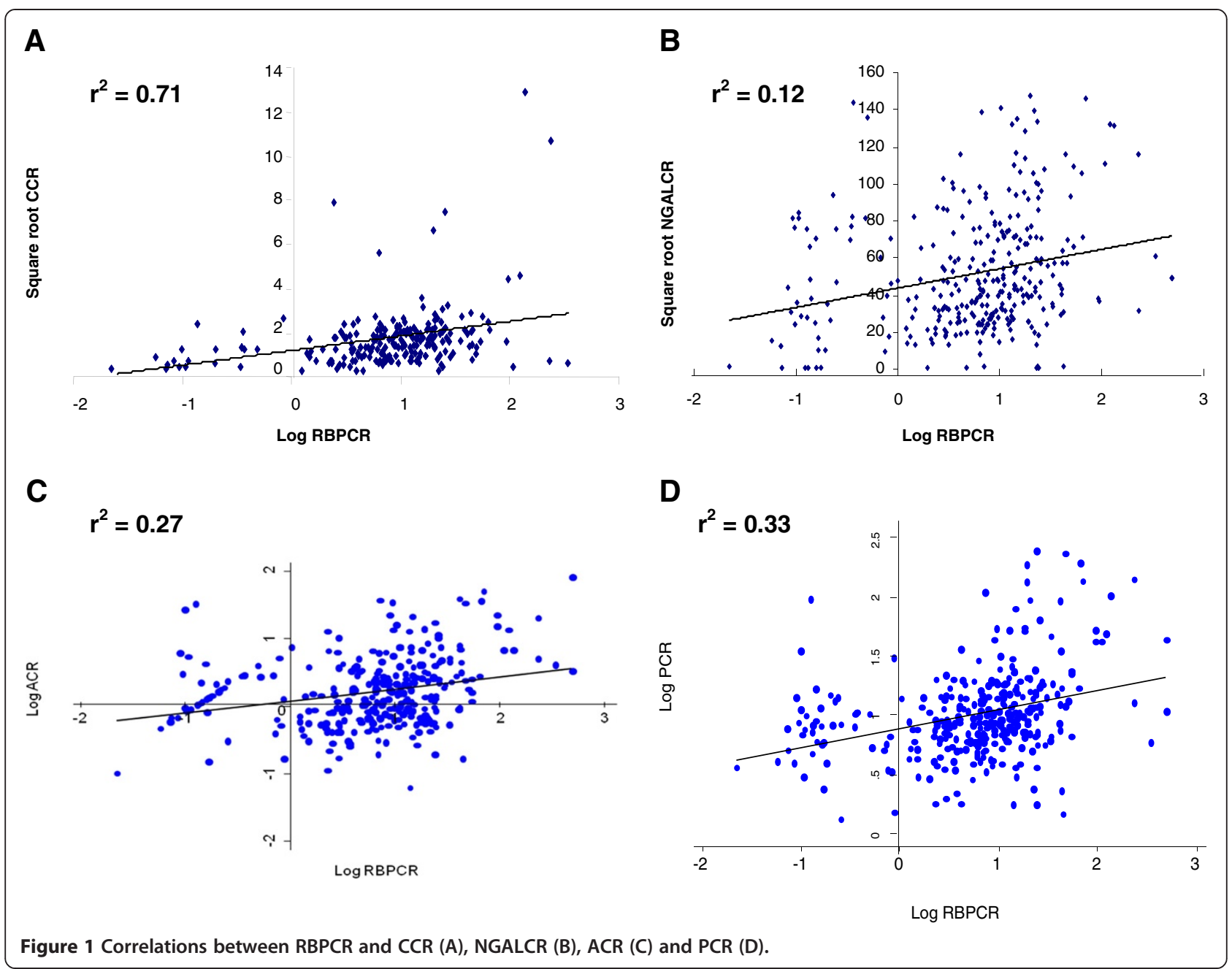

higher RBPCR measurements (data not shown). Black ethnicity was the only factor associated with UQ NGALCR (OR 0.53 [0.32, 0.88], $\mathrm{p}=0.01$ ) and higher current CD4 cell counts the only factor associated with UQ CCR (OR 0.99 [0.99, 0.99], $\mathrm{p}=0.03$ ) in univariate analysis; multivariate analyses were thus not performed. Black ethnicity was marginally associated with UQ CCR (OR 0.59 [0.33, 1.08], $\mathrm{p}=0.09$ ) while impaired renal function and TFV/PI exposure were not related to higher odds of UQ NGAL or CCR.

\section{Discussion}

This study aimed to evaluate urinary concentrations of three LMWP in relation to total urinary protein and albumin in a multiethnic HIV cohort and study potential associations of these parameters with the type of cART used. We observed poor correlations between LMWP and PCR or ACR, and no significant overall differences in urine PCR, ACR and LMWP excretion between patients stratified by cART and TFV exposure. RBPCR in 95\% of patients was within the reference range. By contrast,
$67 \%$ of patients had elevated NGALCR measurements. Black ethnicity was associated with reduced urinary concentrations of LMWP, and impaired renal function with increased urinary RBP concentrations.

Urinary RBP and cystatin $\mathrm{C}$ have previously been proposed as biomarkers for monitoring tubular function in HIV positive patients receiving TFV [25,33]. In a recent clinical trial, a 50\% increase in urinary RBP excretion was observed in patients who initiated TFV with an NNRTI, with no change in the abacavir arm [30]. In a previous cross-sectional study, Hall and colleagues reported increased urinary RBP levels in patients receiving cART including TFV, compared to patients receiving cART without tenofovir or cART naive patients [25]. Our study differed from the latter study in that it included a 3-fold larger cohort, further stratified patients by TFV/NNRTI and TFV/PI exposure, and conducted a multivariate analysis of factors associated with UQ RBPCR measurements.

The absence of a significant association between raised RBPCR and TFV exposure in general, or TFV/PI exposure 


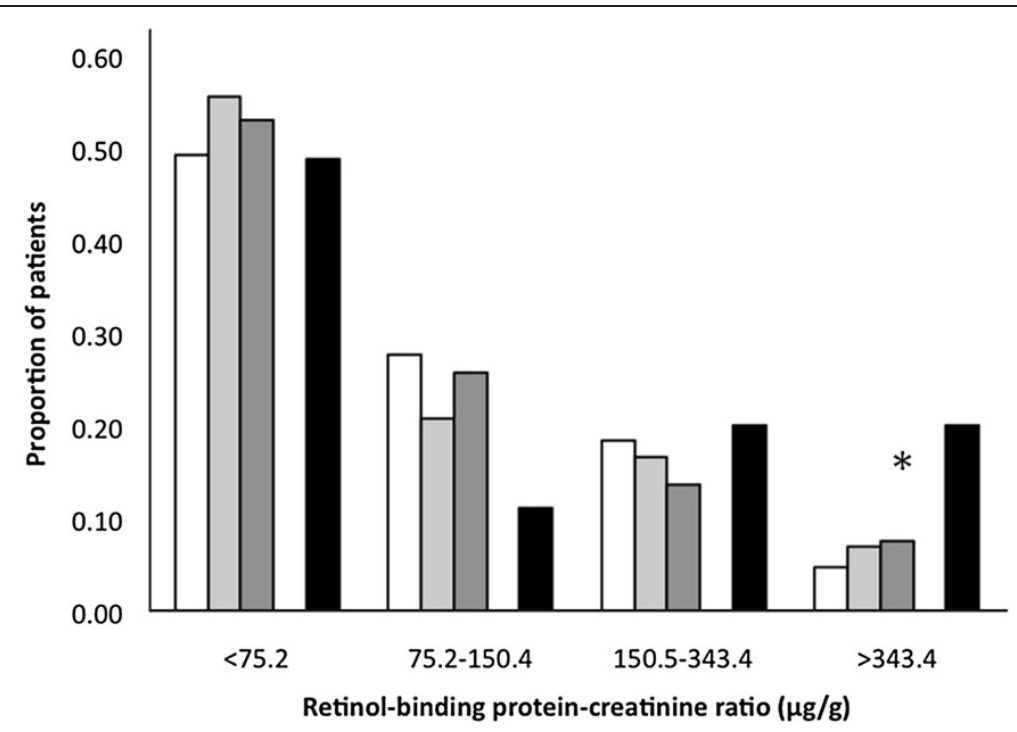

Figure 2 Proportion of patients from the four treatment groups at different levels of retinol-binding protein to creatinine ratio. ${ }^{*} \mathrm{P}=0.003$ (TFV/PI vs. other groups in patients with RBPCR $>343.4 \mu \mathrm{g} / \mathrm{g}$ ). Proportion of patients, stratified by cART exposure (no cART: open bars, CART without TFV: light grey bars, TFV/NNRTI: dark grey bars, TFV/PI: black bars) with retinol-binding protein-creatinine ratio values in the indicated range.

Table 3 Crude and multivariate-adjusted odds ratios of upper quartile RBPCR

\begin{tabular}{|c|c|c|c|c|}
\hline & OR $(95 \% \mathrm{Cl})$ & P-value & Adjusted OR (95\% Cl) & P-value \\
\hline Age (per 10 years increase) & $1.65(1.24,2.19)$ & $<0.001$ & $1.16(0.82,1.64)$ & 0.46 \\
\hline Gender (male v female) & $1.82(0.99,3.31)$ & 0.05 & & \\
\hline Black ethnicity & $0.36(0.22,0.61)$ & $<0.0001$ & $0.43(0.24,0.77)$ & 0.005 \\
\hline Hypertension & $1.37(0.65,2.89)$ & 0.40 & & \\
\hline Diabetes & $1.15(0.29,4.46)$ & 0.84 & & \\
\hline HBsAg (positive) & $0.44(0.09,2.00)$ & 0.29 & & \\
\hline HCV Antibody (positive) & $0.99(0.04,2.81)$ & 0.98 & & \\
\hline \multicolumn{5}{|l|}{ eGFR } \\
\hline$\geq 90 \mathrm{~mL} / \mathrm{min} / 1.73 \mathrm{~m} 2$ & 1 & & 1 & \\
\hline 75-89 mL/min/1.73 m2 & $1.91(1.02,3.57)$ & 0.04 & $1.70(0.88,3.28)$ & 0.13 \\
\hline$<75 \mathrm{~mL} / \mathrm{min} / 1.73 \mathrm{~m} 2$ & $5.52(2.78,10.9)$ & $<0.0001$ & $3.54(1.61,7.80)$ & 0.001 \\
\hline Time since HIV diagnosis (per year increase) & $1.08(1.03,1.14)$ & 0.003 & $1.02(0.96,1.08)$ & 0.4 \\
\hline Nadir CD4 count (per 50 cell increase) & $1.03(0.95,1.12)$ & 0.47 & & \\
\hline Current CD4 count (per 50 cell increase) & $1.03(0.98,1.09)$ & 0.28 & & \\
\hline Current HIV RNA $<50 \mathrm{c} / \mathrm{mL}$ & $0.86(0.51,1.47)$ & 0.61 & & \\
\hline AIDS (CDC status C) & $0.86(0.04,1.66)$ & 0.65 & & \\
\hline \multicolumn{5}{|l|}{ CART status } \\
\hline not on CART & 1 & & 1 & \\
\hline on CART not containing TFV & $1.13(0.53,2.37)$ & 0.76 & $1.23(0.51,2.99)$ & 0.65 \\
\hline on TFV/NNRTI & $1.16(0.50,2.68)$ & 0.73 & $1.06(0.40,2.78)$ & 0.91 \\
\hline on TFV/PI & $2.50(1.04,5.98)$ & 0.04 & $2.40(0.84,6.86)$ & 0.10 \\
\hline
\end{tabular}

$\mathrm{RBPCR}=$ retinol-binding protein-creatinine ratio (urine); 
more specifically, may relate to the fact that our patients had no evidence of clinical renal tubular toxicity, the size and heterogeneity of the cohort, the assay or the RBPCR cut-off chosen for our analyses, or unmeasured confounding. Of note, the median RBPCR in a previous study of patients with TFV-induced Fanconi syndrome was $5593 \mu \mathrm{g} / \mathrm{mmol}(49,515 \mu \mathrm{g} / \mathrm{g})$ [21], which is approximately 100-fold higher than the upper limit of the reference range of the assay used in our study. As almost all of our patients had RBPCR measurements within (or slightly above) the reference range, RBPCR appears to have good discriminatory value between severe, treatment-limiting renal tubular disease and normal tubular function or mild, asymptomatic renal tubular dysfunction.

HIVAN is the predominant cause of end-stage kidney disease in black patients with HIV infection $[3,4,11,12]$. In more advanced cases of HIVAN, urinary NGAL concentrations are typically elevated, and NGAL has been put forward as a useful urinary biomarker to aid the diagnosis of HIVAN [37,38]. Given the strong ethnic predisposition of HIVAN and that this condition may be present in patients with preserved renal function and mild proteinuria [39], it was surprising to find black ethnicity to be associated with lower odds of UQ NGALCR. However, as HIVAN affects only a small proportion of black patients in the UK [4], it is possible that increased urinary NGAL levels in those with (subclinical) HIVAN were masked by generally lower NGAL levels in black patients without HIVAN.

Our results suggest that RBPCR results may need to be interpreted in the context of eGFR and ethnicity. The observed association between ethnicity and tubular biomarkers is of interest and suggests that tubular handling of LMWP may be different in patients of different ethnic backgrounds, or that the prevalence of genetic polymorphisms of the organic anion transporters and/or multi-drug resistant proteins, which have been implicated in the pathogenesis of cART-associated tubular dysfunction $[27,40]$, may vary by ethnicity. Alternatively, a higher muscle mass in black patients may have resulted in higher urinary creatinine concentrations, and thus somewhat lower RBPCR, NGALCR and CCR values.

In our cohort, NGALCR poorly correlated with either RBPCR or CCR. Although all these LMWP are generally proposed as biomarkers of proximal tubular dysfunction, the lack of correlation may suggest that urinary NGAL and RBP or cystatin $\mathrm{C}$ reflect different types and/or severity of tubular dysfunction. NGAL is considered to be a sensitive, early marker of acute kidney injury (acute tubular necrosis), i.e. of a state of extensive global injury of proximal tubular cells [35]. By contrast, RBP and cystatin $\mathrm{C}$ may be better markers of specific forms of proximal tubular dysfunction (such as inherited forms of Fanconi syndrome) [41] or states where proximal tubular dysfunction relates to mitochondrial toxicity and thus a decrease in energy supply - and not to actual necrosis [21].

In the FRAM study, microalbuminuria was present in $11 \%$ of HIV positive patients, and associated with several cardiovascular risk factors including insulin resistance and hypertension, as well as immunodeficiency [42]. Several studies in the general population suggest that urine albumin excretion at the level of microalbuminuria associates with increased risk of cardiovascular events and death, whereas protein excretion at the level of macroalbuminuria or clinical proteinuria (i.e. urine protein $>0.5 \mathrm{~g} /$ day) predicts both cardiovascular events and CKD progression [43]. The associations of elevated albumin and protein excretion with future risks of developing renal failure, cardiovascular events and death have also been confirmed in studies in HIV positive patients [44-47], and thus, urine albumin and protein excretion should be assessed and taken into account in cardiovascular and CKD risk reduction strategies.

This study has several limitations. It followed a crosssectional design and, thus, longitudinal associations could not be evaluated. We relied on a single PCR, ACR and LMWP measurement for our analyses, and we lacked data on phosphate reabsorption or renal histology. Despite the overall sample size, the number of patients receiving TFV/PI was relatively small, and HIV negative controls were not included. Nonetheless, the ethnically diverse participants in our study are representative of the HIV population in the UK, and patients were only selected by their willingness to participate in the study and not for the presence or absence of specific clinical characteristics.

\section{Conclusions}

This study suggests that urinary LMWP concentrations in HIV positive patients are unrelated to viral replication or exposure to cART in general, or exposure to TFV specifically. RBPCR was within the reported range in 95\% of our study subjects, suggesting that RBP may be a useful marker to distinguish patients with normal tubular function or mild tubular dysfunction from those with clinically significant renal tubular disease and Fanconi syndrome.

\section{Competing interests}

EC, LH and FAP have received funding to attend conferences or educational meetings from GlaxoSmithKline, ViiV healthcare, Bristol-Myers Squibb, Jansen-Cilag, Abbott Laboratories and Gilead Sciences. BMH has received honoraria for consultancy from Abbott Laboratories, AM Pharma and Gilead Sciences. RAS has received honoraria for presentations at conferences and preparation of educational material from Siemens Healthcare Diagnostics. FAP has received honoraria from Gilead Sciences, Bristol-Myers Squibb, Janssen-Cilag, GlaxoSmithKline, ViiV healthcare, Merck and Roche, and research funding from Bristol-Myers Squibb, GlaxoSmithKline and ViiV healthcare. All others: no conflict. 


\section{Authors' contributions}

CFM, BMH, RAS and FAP designed the study. LC, EC, LH and FAP collected samples and clinical information. TD, RS, RAS and CFM performed the laboratory assays. LJC performed the statistical analyses with input from $\mathrm{Fl}$, CFM, BMH, MP, RAS and FAP. FAP and PAS wrote the manuscript with input from all authors. The final version of the manuscript was approved by all authors.

\section{Acknowledgements}

The authors would like to thank Dr AG Norden for providing helpful comments during the preparation of this manuscript.

Financial Support

Funding for this study was obtained from the GlaxoSmithKline (grant COL106910 to FAP). The funder was not involved in study design, data analysis, interpretation of the results, writing of the manuscript, or the decision to submit the manuscript. Lisa Hamzah is the recipient of a Doctoral Fellowship Award, National Institute for Health Research, UK.

\section{Author details}

'Academic Department of Renal Sciences, King's College London, London, United Kingdom. ${ }^{2}$ Departments of Clinical Biochemistry, King's College Hospital, London, United Kingdom. ${ }^{3}$ Sexual Health, King's College Hospital, London, United Kingdom.

Received: 13 January 2012 Accepted: 7 August 2012

Published: 10 August 2012

\section{References}

1. Post FA, Holt SG: Recent developments in HIV and the kidney. Curr Opin Infect Dis 2009, 22(1):43-48.

2. Lucas GM, Eustace JA, Sozio S, Mentari EK, Appiah KA, Moore RD: Highly active antiretroviral therapy and the incidence of HIV-1-associated nephropathy: a 12-year cohort study. AIDS 2004, 18(3):541-546.

3. Szczech LA, Gupta SK, Habash R, Guasch A, Kalayjian R, Appel R, Fields TA, Svetkey LP, Flanagan KH, Klotman PE, et al: The clinical epidemiology and course of the spectrum of renal diseases associated with HIV infection. Kidney Int 2004, 66(3):1145-1152.

4. Post FA, Campbell L, Hamzah L, Collins L, Jones R, Siwani R, Johnson L, Fisher M, Holt SG, Bhagani S, et al: Predictors of renal outcome in HIV-associated nephropathy. Clin Infect Dis 2008, 46(8):1282-1289.

5. Choi Al, Shlipak MG, Hunt PW, Martin JN, Deeks SG: HIV-infected persons continue to lose kidney function despite successful antiretroviral therapy. AIDS 2009, 23(16):2143-2149.

6. El-Sadr WM, Lundgren JD, Neaton JD, Gordin F, Abrams D, Arduino RC Babiker A, Burman W, Clumeck N, Cohen CJ, et al: CD4+ count-guided interruption of antiretroviral treatment. N Engl J Med 2006, 355(22):2283-2296.

7. Reid A, Stohr W, Walker AS, Williams IG, Kityo C, Hughes P, Kambugu A, Gilks CF, Mugyenyi P, Munderi P, et al: Severe renal dysfunction and risk factors associated with renal impairment in HIV-infected adults in Africa initiating antiretroviral therapy. Clin Infect Dis 2008, 46(8):1271-1281.

8. Kalayjian RC, Franceschini N, Gupta SK, Szczech LA, Mupere E, Bosch RJ, Smurzynski M, Albert JM: Suppression of HIV-1 replication by antiretroviral therapy improves renal function in persons with low CD4 cell counts and chronic kidney disease. AIDS 2008, 22(4):481-487.

9. Longenecker CT, Scherzer R, Bacchetti P, Lewis CE, Grunfeld C, Shlipak MG: HIV viremia and changes in kidney function. AIDS 2009, 23(9):1089-1096.

10. Ibrahim F, Naftalin C, Cheserem E, Roe J, Campbell L, Bansi L, Hendry BM, Sabin C, Post FA: Immunodeficiency and renal impairment are risk factors for HIV-associated acute renal failure. AIDS 2010, 24(14):2239-2244.

11. Atta MG, Gallant JE, Rahman MH, Nagajothi N, Racusen LC, Scheel PJ, Fine DM: Antiretroviral therapy in the treatment of HIV-associated nephropathy. Nephrol Dial Transplant 2006, 21(10):2809-2813.

12. Bansi L, Hughes A, Bhagani S, Mackie NE, Leen C, Levy J, Edwards S, Connolly J, Holt SG, Hendry BM, et al: Clinical epidemiology of HIVassociated end-stage renal failure in the UK. AIDS 2009, 23(18):2517-2521.

13. Mocroft A, Kirk O, Gatell J, Reiss P, Gargalianos P, Zilmer K, Beniowski M, Viard JP, Staszewski S, Lundgren JD: Chronic renal failure among HIV-1-infected patients. AIDS 2007, 21(9):1119-1127.

14. Mocroft A, Kirk O, Reiss P, De Wit S, Sedlacek D, Beniowski M, Gatell J, Phillips AN, Ledergerber B, Lundgren JD: Estimated glomerular filtration rate, chronic kidney disease and antiretroviral drug use in HIV-positive patients. AIDS 2010, 24(11):1667-1678.

15. Campbell LJ, Ibrahim F, Fisher M, Holt SG, Hendry BM, Post FA: Spectrum of chronic kidney disease in HIV-infected patients. HIV Med 2009, 10(6):329-336.

16. Prevention and management of non-infectious co-morbidities in HIV. http:// www.europeanaidsclinicalsociety.org/images/stories/EACS-Pdf/ eacsguidelines-6.pdf.

17. Gupta SK, Eustace JA, Winston JA, Boydstun II, Ahuja TS, Rodriguez RA, Tashima KT, Roland M, Franceschini N, Palella FJ, et al: Guidelines for the management of chronic kidney disease in HIV-infected patients: recommendations of the HIV Medicine Association of the Infectious Diseases Society of America. Clin Infect Dis 2005, 40(11):1559-1585.

18. Asboe D, Aitken C, Boffito M, Booth C, Cane P, Fakoya A, Geretti AM, Kelleher P, Mackie N, Muir D, et al: British HIV Association guidelines for the routine investigation and monitoring of adult HIV-1-infected individuals 2011. HIV Med 2012, 13(1):1-44.

19. Izzedine H, Deray G: The nephrologist in the HAART era. AIDS 2007 , 21(4):409-421

20. Zimmermann AE, Pizzoferrato T, Bedford J, Morris A, Hoffman R, Braden G: Tenofovir-associated acute and chronic kidney disease: a case of multiple drug interactions. Clin Infect Dis 2006, 42(2):283-290.

21. Woodward CL, Hall AM, Williams IG, Madge S, Copas A, Nair D, Edwards SG, Johnson MA, Connolly JO: Tenofovir-associated renal and bone toxicity. HIV Med 2009, 10(8):482-487.

22. Peyriere H, Reynes J, Rouanet I, Daniel N, de Boever CM, Mauboussin JM, Leray H, Moachon L, Vincent D, Salmon-Ceron D: Renal tubular dysfunction associated with tenofovir therapy: report of 7 cases. J Acquir Immune Defic Syndr 2004, 35(3):269-273.

23. Izzedine H, Isnard-Bagnis C, Hulot JS, Vittecoq D, Cheng A, Jais CK, Launay-Vacher V, Deray G: Renal safety of tenofovir in HIV treatmentexperienced patients. AIDS 2004, 18(7):1074-1076.

24. Labarga P, Barreiro P, Martin-Carbonero L, Rodriguez-Novoa S, Solera C, Medrano J, Rivas P, Albalater M, Blanco F, Moreno V, et al: Kidney tubular abnormalities in the absence of impaired glomerular function in HIV patients treated with tenofovir. AIDS 2009, 23(6):689-696.

25. Hall AM, Edwards SG, Lapsley M, Connolly JO, Chetty K, O'Farrell S, Unwin RJ, Williams IG: Subclinical tubular injury in HIV-infected individuals on antiretroviral therapy: a cross-sectional analysis. Am J Kidney Dis 2009, 54(6):1034-1042

26. Fux C, Opravil M, Cavassini M, Calmy A, Flepp M, Gurtner-Delafuente V, Stoeckle M, Schmid P, Rauch A, Furrer H, et al: 16th Conference on Retroviruses and Opportunistic Infections. In Tenofovir and PI Use Are Associated with an Increased Prevalence of Proximal Renal Tubular Dysfunction in the Swiss HIV Cohort Study. Canada: Montreal; 2009.

27. Rodriguez-Novoa S, Labarga P, Soriano V, Egan D, Albalater M, Morello J, Cuenca L, Gonzalez-Pardo G, Khoo S, Back D, et al: Predictors of kidney tubular dysfunction in HIV-infected patients treated with tenofovir: a pharmacogenetic study. Clin Infect Dis 2009, 48(11):e108-116.

28. Rodriguez-Novoa S, Labarga P, D'Avolio A, Barreiro P, Albalate M, Vispo E, Solera C, Siccardi M, Bonora S, Di Perri G, et al: Impairment in kidney tubular function in patients receiving tenofovir is associated with higher tenofovir plasma concentrations. AIDS 2010, 24(7):1064-1066.

29. Ando M, Yanagisawa N, Ajisawa A, Tsuchiya K, Nitta K: Kidney tubular damage in the absence of glomerular defects in HIV-infected patients on highly active antiretroviral therapy. Nephrol Dial Transplant 2011, 26(10):3224-3229.

30. Post FA, Moyle GJ, Stellbrink HJ, Domingo P, Podzamczer D, Fisher M, Norden AG, Cavassini M, Rieger A, Khuong-Josses MA, et al: Randomized Comparison of Renal Effects, Efficacy, and Safety With Once-Daily Abacavir/Lamivudine Versus Tenofovir/Emtricitabine, Administered With Efavirenz, in Antiretroviral-Naive, HIV-1-Infected Adults: 48-Week Results From the ASSERT Study. J Acquir Immune Defic Syndr 2010, 55(1):49-57.

31. Horberg M, Tang B, Towner W, Silverberg M, Bersoff-Matcha S, Hurley L, Chang J, Blank J, Quesenberry C Jr, Klein D: Impact of tenofovir on renal function in HIV-infected, antiretroviral-naive patients. J Acquir Immune Defic Syndr 2010, 53(1):62-69.

32. Pushpakom SP, Liptrott NJ, Rodriguez-Novoa S, Labarga P, Soriano V, Albalater M, Hopper-Borge E, Bonora S, Di Perri G, Back DJ, et al: Genetic Variants of ABCC10, a Novel Tenofovir Transporter, Are Associated With Kidney Tubular Dysfunction. J Infect Dis 2011, 204(1):145-153. 
33. Jaafar A, Seronie-Vivien S, Malard L, Massip P, Chatelut E, Tack I: Urinary cystatin C can improve the renal safety follow-up of tenofovir-treated patients. AIDS 2009, 23(2):257-259.

34. Post FA, Wyatt CM, Mocroft A: Biomarkers of impaired renal function. Curr Opin HIV AIDS 2010, 5(6):524-530.

35. Mishra J, Dent C, Tarabishi R, Mitsnefes MM, Ma Q, Kelly C, Ruff SM, Zahedi K, Shao M, Bean J, et al: Neutrophil gelatinase-associated lipocalin (NGAL) as a biomarker for acute renal injury after cardiac surgery. Lancet 2005, 365(9466):1231-1238.

36. Mancia G, De Backer G, Dominiczak A, Cifkova R, Fagard R, Germano G, Grassi G, Heagerty AM, Kjeldsen SE, Laurent S, et al: 2007 Guidelines for the Management of Arterial Hypertension: The Task Force for the Management of Arterial Hypertension of the European Society of Hypertension (ESH) and of the European Society of Cardiology (ESC). $J$ Hypertens 2007, 25(6):1105-1187.

37. Sola-Del Valle DA, Mohan S, Cheng JT, Paragas NA, Sise ME, D'Agati VD, Barasch J: Urinary NGAL is a useful clinical biomarker of HIV-associated nephropathy. Nephrol Dial Transplant 2011, 26(7):2387-2390.

38. Paragas $N$, Nickolas TL, Wyatt C, Forster CS, Sise M, Morgello S, Jagla B, Buchen C, Stella P, Sanna-Cherchi S, et al: Urinary NGAL marks cystic disease in HIV-associated nephropathy. J Am Soc Nephrol 2009, 20(8):1687-1692.

39. Han TM, Naicker S, Ramdial PK, Assounga AG: A cross-sectional study of HIV-seropositive patients with varying degrees of proteinuria in South Africa. Kidney Int 2006, 69(12):2243-2250.

40. Izzedine H, Hulot JS, Villard E, Goyenvalle C, Dominguez S, Ghosn J, Valantin MA, Lechat P, Deray AG: Association between ABCC2 Gene Haplotypes and Tenofovir-Induced Proximal Tubulopathy. J Infect Dis 2006, 194(11):1481-1491.

41. Burling KA, Cutillas PR, Church D, Lapsley M, Norden AG: Analysis of molecular forms of urine Retinol-Binding Protein in Fanconi Syndrome and design of an accurate immunoassay. Clin Chim Acta 2012, 413(3-4):483-489.

42. Szczech LA, Grunfeld C, Scherzer R, Canchola JA, van der Horst C, Sidney S, Wohl D, Shlipak MG: Microalbuminuria in HIV infection. AIDS 2007, 21(8):1003-1009.

43. Sarafidis PA, Bakris GL: Microalbuminuria and chronic kidney disease as risk factors for cardiovascular disease. Nephrol Dial Transplant 2006, 21(9):2366-2374

44. Gardner LI, Holmberg SD, Williamson JM, Szczech LA, Carpenter CC, Rompalo AM, Schuman P, Klein RS: Development of proteinuria or elevated serum creatinine and mortality in HIV-infected women. J Acquir Immune Defic Syndr 2003, 32(2):203-209.

45. Choi Al, Li Y, Deeks SG, Grunfeld C, Volberding PA, Shlipak MG: Association between kidney function and albuminuria with cardiovascular events in HIV-infected persons. Circulation 2010, 121(5):651-658.

46. George E, Lucas GM, Nadkarni GN, Fine DM, Moore R, Atta MG: Kidney function and the risk of cardiovascular events in HIV-1-infected patients. AIDS 2010, 24(3):387-394

47. Wyatt CM, Hoover DR, Shi Q, Seaberg E, Wei C, Tien PC, Karim R, Lazar J, Young MA, Cohen MH, et al: Microalbuminuria is associated with all-cause and AIDS mortality in women with HIV infection. J Acquir Immune Defic Syndr 2010, 55(1):73-77.

\section{doi:10.1186/1471-2369-13-85}

Cite this article as: Campbell et al:: Total protein, albumin and low-molecular-weight protein excretion in HIV-positive patients. BMC Nephrology 2012 13:85.

\section{Submit your next manuscript to BioMed Central and take full advantage of:}

- Convenient online submission

- Thorough peer review

- No space constraints or color figure charges

- Immediate publication on acceptance

- Inclusion in PubMed, CAS, Scopus and Google Scholar

- Research which is freely available for redistribution 